\title{
ON LOSS OF BOTH KNEE-JERKS FROM ONE-SIDED BRAIN DISEASE.
}

\author{
BY STEPHEN MACKENZIE, M.D., F.R.C.P.
}

Physician to, and Lecturer on Medicine at, the London Hospital.

I PROPOSE to discuss a very interesting phenomenon, which offers considerable difficulty of explanation, namely, the loss of both knee-jerks from a unilateral cerebral lesion. It will, I think, be found that the condition is not by any means of rare occurrence, but attention has, as far as I know, scarcely been called to it, and I an not aware of any explanation that has been advanced concerning it. It will perhaps be most convenient if $I$ first relate a case in which the phenomenon existed. It was a case of gliomatous tumour of one hemisphere cansing hemiplegia and hemianasthesia, whilst the patient had complete loss of both knee-jerks. The case is as follows :-

M. N., aged 25, came to the Ophthalmic department of the London Hospital for defect of sight, on the 8th of January, 1880. My colleague, Mr. Waren Tay, under whose care she came, noted " Myopia; changes in yellow spot region (resulting from hæmorrhage?)

$$
\begin{aligned}
& \text { L. } 3 \frac{1}{2} \text { Snellen } \frac{20}{0}-3 \text { D } \frac{20}{70} \\
& \text { R. } 3 \frac{1}{2} \text { Snellin }-11 \text { D } \frac{20}{100}
\end{aligned}
$$

Evidences of neuritis, with hæmorrhages, in left eye." On the 15th of March, when seen again, Mr. Tay noted: "The right disc is now distinctly swollen, the margins obscure, and there also appear to be small nodules of lymph here and there. In addition, of course, are the myopic patches of more or less exposed sclerotic. No hæmorrhages detected in right eye. In left eye, well marked swollen disc, with lymph and hæmorrhages." 
The following history of the case was elicited by Mr. Tay and Mr. Makeham, then my clinical clerk:

"Family history unimportant. The patient was backward in teething and walking, and at school, in learning. She had a discharge from her ears, accompanied by pain, from the age of three until dentition was completed. When 9 years of age had disease of right hip, following scarlet fever, which left her permanently lame. Since the age of 15 has been engaged as a milliner.

“ Just before Christmas, 1879, she complained of pains in the head, and of a cold numb feeling down her right side. On the 7 th of February, 1880, she appeared to lose her sight almost entirely and somewhat suddenly, but she had complained of defect of vision since the beginning of the year, and as already stated she was seen by Mr. Tay on the 24th of January, and her condition then noted. At the time when the loss of sight became nearly complete she had very severe frontal headache. One week before admission she had two fits, with an interval of fifteen minutes between them. In the fits she was unconscious, and had convulsire movements almost confined to the right side. When she came out of the fit she squinted a little, temporarily. Since the fits she has not been able to walk, has seemed very drowsy, and has slept a good deal. Mr. Tay, recognising the nature of the case, asked me to see the patient on the 20th of March, when I made the following note:

" The right hand and arm are feeble. She drags the right $\operatorname{leg}$ in a feeble way, and has not power to stand on it. She cannot stand or walk at all unassisted. The pain in the head is very severe, and only relieved temporarily by hypodermic injections of morphia. There are occasional movements of right eye, inwards and a little downwards, independently of the movements of the left eye. These movements are increased when she looks to the left. The external rectus of each eye appears feeble. The double optic neuritis, severe pain in heud, vomiting, and slow onset of paralysis, all point to tumour of the brain."

The patient was transferred by Mr. Tay to my care on the 20th of March, when it was noted as follows: the eyeballs

vol. vi. 
are prominent, the corneo-sclerotic junction being seen all round when she opens her eyes. Can just see moving objects. Tongue clean, bowels much confined. No abnormal physical signs in chest.

As already mentioned there is decided loss of power in the right arm and leg, but no facial paralysis or deflection of the tongue are detected. There is entire absence of both knee-jerlss.

April 1st.-Yesterday afternoon facial paralysis was noticed by the sister of the ward. To-day the mouth is slightly drawn to the left. When she parts her lips the mouth is much more arched on the left side. The right eye closes imperfectly upon making an effort. The left eye winks naturally, whilst the right scarcely moves. When she frowns no wrinkles can be seen on the right side. The tongue on protrusion is slightly deflected and curved to the right. Uvula not deflected. Sensation to heat, cold, pain, and ordinary tactile impressions are impaired on the right side. She cannot move the right lower extremity. There is complete loss of both knee-jerks. No increase of plantar reflex on right side. She cannot walk now, even with assistance.

April 3rd.-Complains of constant headache. No vomiting. Facial paralysis still more marked. Cannot hear a watch close up to right ear. Smell absent. Taste normal.

April 6th.- Since the 2nd of April has not been able to distinguish night from day.

April 9th.--I noted the paralysis of motion of right face, arm, and leg is very complete. Owing to the patient's blindness, it is difficult to test the ocular movements, and all that can be said is that the right superior rectus does not move so freely as its fellow. There is marked, but not complete, loss of sensation on the right side of face, and the sensation of the right arm and leg is very much impaired, being only observed on deep pricking. She can now hear a watch with right ear at about one inch distant, on the left side at four inches distant. There has been no incontinence of urine or fæces.

April 12th.-Facial paralysis less marked. Can feel better the prick of a pin. She has also regained to a very slight degree the movement of both upper and lower right extremities. 
April 19th.-Complains very much of pain in the head. Has romited several times the last few days.

April 20th.-The minute vascular injection of the leit dise is less conspicuous, the tissues being more opaque. The retinal veins are very large and tortuous, the arteries small, and there are a number of hæmorrhages on and around the disc. Between the disc and the yellow spot are a number of white striæ converging to the latter point. Her urine contained a trace of albumen on admission, none since.

April 23rd.-The left eye appears slightly more prominent than the right. The palpebral fissure is smaller on the right side, apparently owing to want of tone, for she can both open and close the eyelids, but she closes the right more freely than the left. The movements of the eyes are limited in all directions, especially upwards.

April 28th.-Has become more and more helpless, the pain in the head has been very severe lately.

April 29th.-Swelling of right upper lid, conjunctiva injected, and one or two abrasions over cornea. The whole of right side of face is injected, and there is a profuse mucous discharge from the right nostril.

May 2nd.-Patient complains of pain in the left extremities"As if they are being pulled away from me," she says. She is losing power on the left side, this has been noticed for some days. She cannot draw up the left leg: cannot lift the left arm from the bedclothes; the grasp of the hand is very feeble. No anrsthesia on left side.

May 6th.-Suffocative attack, associated with a choking cough, in which she became livid in the face.

May 9th.-After a trifling improvement is again worse. She has had another "choking fit" to-day, this being the third. They come on after drinking something, and nurse says, "she seems as if she had not sense enough to swallow properly." Following this last attack she sank into an unconscious condition, the heart's action became irregular and intermittent, the respiration feeble and gasping, and she died at 10.10 P.M.

The vecropsy was made on the following day. The detailed rescription of what was found is mislaid, but the following 
transcript from the abridged post mortem records supplies all that is essential to be conveyed:

"Glioma of left hemisphere (with hæmorrhage) involving left corpus striatum and thalamus opticus, and extending down crus cerebri to its junction with the pons. No changes in viscera except venous congestion."

The spinal cord showed no changes to the naked eye. It was hardened in bichromate of ammonia, and has since been examined. Sections from cervical, dorsal, and lumbar regions show no descending wasting, and no changes of any importance.

There are several points of interest in this case, to which I may in passing allude.

I. That the symptoms, though not strictly beginning in the eye, so far predominated there that the patient first came under the care of the ophthalmic surgeon. When first seen by Mr. Tay there was unilateral neuritis. It was the left eye which was first afferted with inflammation and the disease causing it was also on the left side of the brain. As I have shown ${ }^{1}$ when optic neuritis is unilateral it has usually been on the side opposite to the growth. Dr. Emest Field ${ }^{2}$ has also recorded a case illustrating this fact. But whilst I think this is often the case, it is clearly not, and I did not in drawing attention to the point intend to imply that it was, invariable. As regards the ocular movements and paresis, but little can be said, but the tumour involving the thalamus was in close propinquity to the centre discovered by Adamuk in the corpora quadrigemina and thus may be explained the movements and weakness of the muscles of the right eyeball from disease on the left side of the brain, no disease being found on the right side. Owing to the patient's state these conditions coild not be very accurately studied.

II. The symptoms enabled a localisation of the disease to be made with certuinty. The dysæsthesia followed by anæsthesia pointed to the thalamus opticus or its vicinity : the right sided convulsion followed by gradual and extending paralysis of mution of the right balf of body, pointed, in conjunction with the anresthesia of the same area to disease involving the

1 'Brais,' rol. ii., p. 269.

2 Ibid. vol. iv., p. 249. 
corpus striatum, or anterior part of internal capsule. The severe headache, vomiting and double optic neuritis, made it certain that the local disease was tumour. The absence of syphilis, acquired or congenital, the absence of signs of decided struma, and the age of the patient rendered it probable that the tumour was, as it proved to be, gliomatous.

III. The hæmorrhage into the tumour just before death. I regret that my detailed notes on this point are not available. There was a large black clot in the growth. We know that this not infrequently happens in vascular gliomata, that it may give rise to apoplectiform symptoms, and in the inexperienced, especially in the absence of history, lead to the growth which has bled being overlooked. This would be all the more likely when, as in this case, the growth occupied "the seat of election" of hæmorrhage.

The point to which I especially wish to draw attention in this case, however, is not any of the foregoing, but to the double loss of knee-jerk. It will be observed the cerebral disease was strictly unilateral, the loss of knee reflex double. I believe in this respect this case is by no means an isolated one. I have seen more than one case and know of others in whieh there has been clinical evidence of cerebral tumour with double loss of knee-jerks but in which there was no post mortem. Dr. Hughlings Jackson mentioned at a discussion at the Ophthalmological Society recently a case in which there was local brain disease, but in which no change was found in the cord after death ${ }^{1}$ and since then $I$ have seen the parts from a case of his in which there was unilateral tumour loss of both knee-jerks, and no naked eye changes in the cord at the necropsy. Dr. Hughlings Jackson alluded to other cases he had seen without necropsis.

The loss of knee-jerks from cerebral disease is difficult of explanation. We know that the brain exerts a controlling or inhibitory power over the spinal cord, as regards its reflex functions; and that this inhibition can be increased by a voluntary effort. The exact course of the inhibitory fibres in the brain and cord is not certain, though as regards the latter it is probable that the fibres pass along the pyramidal tracts. 
It is well known that when the cerebral inhibition is removed, as by a destructive lesion between the medulla and the level of the cord, concerned, as a centre, in completing the reflex, exaggerated reflex is the result. How then is it to be explained that a cerebral lesion causes abolition of the reflex?

I venture on the following explanation with the greatest diffidence, and my putting it forward may have the effect of eliciting a better one. Suppose there is an inhibitory centre (or centres) in each hemisphere acting upon the spinal cord as a reflex centre. These centres under ordinary circumstances act together, and control the reflex excitability of the $e_{\gamma}$ cord. Their inhibitory power is capable of being augmented by a voluntary effort, say by means of cortical centres connected by commissural fibres with the inhibitory centres lower down. ${ }^{1}$ The two inhibitory centres naturally act together, each being also connected with both halves of the spinal segment concerned in the reflex, in the same way as motor impulses are conveyed to both halves of the cord by the crossed and direct pyramidal tracts. But being arranged for combined action, if one is injured or destroyed, the other is uncontrolled; and connected as it is with buth halves of the cord, over-inhibits or annuls the reflex affected through both halves of the spinal segment concerned. The injured, or destroyed, normally cooperating inhibitory centre necessurily has its function abolished; and, if there were no other action, this would lead to exaggeration of the reflex governed by the inhibitory centre. But this is prevented by the uncontrolled healthy inhibitory centre whose positive action outweighs the negative action of its destroyed fellow centre. In this way can be explained how a lesion limited to one side of the brain can cause loss of both knee-jerks, and this without there being any structural alteration in the spinal cord. The diagram on page 231 will, I hope, serve to illustrate my meaning.

Let us suppose $\mathrm{A}$ and $\mathrm{B}$, connected by the commissural fibre

1 This is certainly less probable as regards the knee-jerk than as regards the vesical and some other reflexes. I am aware of the powerful arguments against the knce-jerk being a true spinal reflex, but it is enough for the argument to admit, as is unirersally done, that it depends upon a spinal influence. 
$a$, to be iuhibitory centres in each half of the brain ( $\mathrm{R} \mathrm{H}$ and L H), $A$ and $B$ are connected with higher centres $\mathrm{C}$ and $\mathrm{c}^{\prime}$, by which their inhibitory power can be strengthened. From $\Delta$

R. H., right hemisplyere of brain. L. H. left homisphere. A. right cerebral inbibitory centre; B. loft ditto, ditto. C. cortical centres. A. H. ganglion cells of anterior horn of (S. C.) spinal cord. $\mathbf{M}$. muscles moving knee. T. patellar tendon. a. commissural fibres connecting cerebral inhibitory centres: $b$ and $b^{1}$, paths of cerebral inlibitory fibres from left half of brain to toth halves of cord : $c$ and $c^{1}$, paths of corebral inlibitory fibres from right half of brain to both halves of cord. $d$ sensory fibres from patellar tendon to grey matter of cord : $e$ and $e^{1}$, motor fibres from anterior horn to extensor muscles moving knee: $f$ and $f$, fibres from cortex to inhibitory centre.



fibres pass by $\mathbf{c}$ and $\mathrm{c}^{\prime}$ to the right and left of the spinal segment (S C), where, in the anterior horns (A H), they communicate with the ganglionic centres there situated, and exercise their inhibitory function. From B fibres pass by $b$ and $b^{\prime}$ to the spinal segment in similar manner. T represents the patellar tendon ( $I$ assume, for simplicity of argument, that the knee-jerk is a tendon reflex), and $M$ the extensor muscles moving the leg. A stimulus from $\mathbf{T}$ is conveyed along $d$ by the posterior root to the spinal cord, and an efferent impulse sent by the anterior horn along $e$ to the muscles (M). In ordinary circumstances the reflex completed in the spinal segment, say in the anterior horn, is here controlled by the fibres, say from the crossed and direct pyramidal tracts, coming from the inhibitory centre of each side of the brain. Destruction of one half of the cord above the segment concerned in the reflex, involving $b$ and $c$ or $b^{\prime}$ and $c^{\prime}$ will lead to exaggerated knee reflex on the injured side, by removing the influence of both cerebral inhibitory centres; and destruction of both halves of the cord above the segment will lead to exaggerated knee reflex on both sides. This is the explanation usually received.

If, however, there be a lesion of one side of the brain invol- 
ving this inhibitory centre $A$, the influence of $A$ is removed from both halves of the cord; but $B$, being unantagonised, overacts, and being connected with both halves of the cord, annuls both knee reflexes. A difficulty immediately suggests itself as to adequacy of this explanation. In hemiplegia, due to a unilateral cerebral lesion, there is usually exaggeration of the knee-jerk on the paralysed side. This is generally said to be caused, but more correctly described as permitted, by the secondary degeneration of the cord above the spinal segment concerned in the reflex. It would appear to me to be due to, or permitted by, involvement of parts below, $\mathbf{A}$ and $\mathbf{B}$ in $b$ and $c$, or $b^{\prime}$ and $c^{\prime}$, and if so it would not militate against my hypothesis. It will be observed in my case, that though there was right hemiplegia, there was no exaggeration of the knee-reflex on the paralysed side. These corresponded with the absence of descending sclerosis in the spinal cord, and thus harmonises with my hypothesis. ${ }^{1}$

As I have already said, it is not ascertained how the fibres travel to the spinal segment from $A$ and $B$, or whether they are independent of the motor fibres passing from the brain to the cord. This hypothesis, it will be seen, explains how the knee-reflex is exaggerated when there is descending wasting in the cord, and at the same time explains why there need be no lesion in the cord when the reflex is abolished on both sides from a unilateral cerebral lesion, as in the case I have narrated, and as occurs probably not unfrequently. On my hypothesis, if both inhibitory centres were disabled, there would be exaggerated knee-reflex on both sides, from complete removal of all cerebral inhibition, in the same way that a total transverse lesion causes exaggeration of both knee-jerks. I do not know, however, of any facts bearing on this point. ${ }^{2}$

1 The increase of knee-jerk noticed after convulsive seizures would appear to be due to exhaustion of the hypothetical inhibitory centres.

See a very interesting case of loss of both kuec-jerks from tumour of cerebellum, in a case of Dr. Ramskill's, reported by Dr. Coxwell, 'Brit. Med. Journal,' May 19, 1883, p. 957. 